\title{
Risk and sustainability analysis of complex hydrogen infrastructures
}

\author{
Markert, Frank; Marangon, A.; Carcassi, M.; Duijm, Nijs Jan
}

Published in:

International Journal of Hydrogen Energy

Link to article, DOI:

10.1016/j.ijhydene.2016.06.058

Publication date:

2017

Document Version

Peer reviewed version

Link back to DTU Orbit

Citation (APA):

Markert, F., Marangon, A., Carcassi, M., \& Duijm, N. J. (2017). Risk and sustainability analysis of complex hydrogen infrastructures. International Journal of Hydrogen Energy, 42(11), 7698-7706.

https://doi.org/10.1016/j.ijhydene.2016.06.058

\section{General rights}

Copyright and moral rights for the publications made accessible in the public portal are retained by the authors and/or other copyright owners and it is a condition of accessing publications that users recognise and abide by the legal requirements associated with these rights.

- Users may download and print one copy of any publication from the public portal for the purpose of private study or research.

- You may not further distribute the material or use it for any profit-making activity or commercial gain

- You may freely distribute the URL identifying the publication in the public portal

If you believe that this document breaches copyright please contact us providing details, and we will remove access to the work immediately and investigate your claim. 


\title{
Risk and sustainability analysis of complex hydrogen infrastructures
}

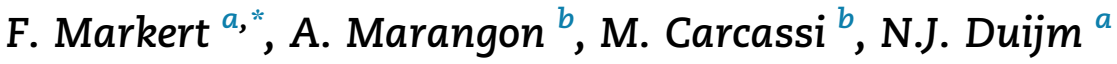 \\ a Institute Management Engineering, Technical University of Denmark, Produktionstorvet 424, 2800, \\ Kongens Lyngby, Denmark \\ ${ }^{\mathrm{b}}$ Industrial and Civil Department, University of Pisa, L. Lazzarino n.2, 56126, Pisa, Italy
}

\section{A R T I C L E I N F O}

Article history:

Received 16 March 2016

Received in revised form

30 May 2016

Accepted 3 June 2016

Available online $\mathrm{xxx}$

Keywords:

Hydrogen refuelling stations

Power systems

Risk assessment

Sustainable assessment

Supply chains

\begin{abstract}
A B S T R A C T
Building a network of hydrogen refuelling stations is essential to develop the hydrogen economy within transport. Additional, hydrogen is regarded a likely key component to store and convert back excess electrical power to secure future energy supply and to improve the quality of biomass-based fuels. Therefore, future hydrogen supply and distribution chains will have to address several objectives. Such a complexity is a challenge for risk assessment and risk management of these chains because of the increasing interactions. Improved methods are needed to assess the supply chain as a whole. The method of "Functional modelling" is discussed in this paper. It will be shown how it could be a basis for other decision support methods for comprehensive risk and sustainability assessments.
\end{abstract}

( 2016 Hydrogen Energy Publications LLC. Published by Elsevier Ltd. All rights reserved.

\section{Introduction}

Developing a hydrogen refuelling station (HRS) network is the next important step to establish hydrogen as a fuel for vehicles and related services. Such stations will most likely be integrated in existing refuelling stations and result in multifuel storages. These will handle, store and distribute various fuels, as e.g. biomass-based methane, ethanol, gasoline, diesel as well as the traditional crude-oil based products. The power sector regards hydrogen storage as a perspective to secure robust power supply when large shares of fluctuating energy sources replace today's power plants. Therefore, hydrogen supply and distribution chains may likely not only serve to fulfil the demands of refuelling, but also may be important for the wider power and fuel industries. Thus, a future hydrogen infrastructure presumably bridges the infrastructures for transport and power supply.

The operation and control of such complex multifunctional hydrogen supply and distribution networks sets higher demands on the decision-making process addressing the safety and sustainability of these systems. The challenge for risk analysts is to treat many threads in a dynamical system, while most tools to ensure safety are designed to deal with individual plants and their components, see for example [1-4]. Risk assessment that compares different alternative technologies as an input to decision making is a demanding task, even for rather simple cases as a HRS. From a systemic perspective, though, it is essential to take a holistic approach, as system safety is more than just the reliability of its single components.

In order to find the optimal methods and processes, strategic decision making need to compare infrastructures taking

\footnotetext{
* Corresponding author.

E-mail addresses: fram@dtu.dk (F. Markert), a.marangon@ing.unipi.it (A. Marangon). http://dx.doi.org/10.1016/j.ijhydene.2016.06.058 0360-3199/@ 2016 Hydrogen Energy Publications LLC. Published by Elsevier Ltd. All rights reserved.
} 
into account networks of refuelling stations including their supply chains. In a number of European countries such as The Netherlands and Italy it is common to use Quantitative Risk Assessments to find the risk of infrastructures as chemical process plants, tunnels and routes for hazardous-goods transport and to use the outcomes of these to support risk informed land-use planning, e.g. Refs. [5-7].

In a broader perspective risk assessment is part of the general decision support to plan, to design and to establish supply chains that are economic, efficient, reliable, safe, secure, and sustainable. The goal is to have a comprehensive approach, combining and evaluating all considerations in a systemic perspective to find the best solution to ensure the decision support for industries, investors and authorities. Such an approach described by Zachmann et al. [8] may support the development of long termed policies and reduce regulatory uncertainties for the private sector, as regulatory uncertainty is found to be a major barrier in implementing new technologies. By that Zachmann et al. [8, p. 5] recommends to establish a transparent and predictable support policy for all competing technologies and suggests technology choice forecasts using new open multi-technology models that "should be built, maintained, extended and published by an independent public institution".

Presently, the scientific literature dealing with the planning and design of hydrogen infrastructures has very limited focus on systems safety. Caputo et al. [9] discuss high safety cost for long-range hydrogen transport through densely populated regions. Kim and Moon [10] predicted the safety costs for an optimized Korean infrastructure partly based on renewable energies. Dayhim et al. [11] implemented risk costs into a multi-period optimization model with the objective function "minimization of the total daily social cost" of a hydrogen supply chain network. Other authors address (e.g. Refs. [12-14]) topics such as the potential growth of supply chain networks, optimization of the investment and running costs. The environmental impacts based on single impact parameters are calculated, as e.g. the carbon dioxide reduction potentials calculated from energy models. StephensRomero et al. [15] performed a case study on the optimal implementation of a HRS network using their Spatially and Temporally Resolved Energy and Environment Tool (STREET). The objective was to show optimized investments for HRS networks, while fulfilling e.g. the environmental standards for California. In some papers, the authors take a more technical approach on modelling the system processes and their related impacts, e.g. Ref. [16]. Here, the focus is on component relations and technical comparisons integrating e.g. fuel transport and energy distribution networks. A study on the development of a possible future supply chain [17] optimizing on the fuel price finds that conversion of fossil fuels into hydrogen may be the main driver, while hydrogen production by electrolysis is negligible. While such a result may be expected using a cost benefit point of view, it certainly conflicts with the goal to design for more sustainable solutions. Therefore, a more comprehensive decision support would be a better approach to plan the new infrastructures.

One challenge applying a more comprehensive approach is the handling of the large amount of data and assumptions in a transparent and comprehensive way. At the same time it is important to address the aleatory and epistemic uncertainties that are unavoidable in such studies and to show the influence of new improved knowledge may have on the outcome of a QRA [18-20].

To better cope with the above-mentioned challenges and the uncertainties involved, the following questions raise: How could such a solution be structured? How can one ensure that the various studies that feed into strategic decisions, such as risk assessment, environmental assessment and economic assessment actually deal with exactly the same system? How to compare and decide on the use of alternative technologies in a consistent way? These issues are very complex and, therefore, they need a broad discussion and further development of tools. This paper presents one possible methodology that could help to structure the risk assessment process.

Based on an integrated hydrogen supply and distribution network, the application of the method of "Functional modelling" is presented to show a framework for describing the coupling of functions in a complex hydrogen supply and distribution network, where interferences and strong connections can be found between power storage for electricity supply and supplying hydrogen for transportation. The method "Functional modelling" is described together with a few other decision support tools as Life Cycle Assessment (LCA) and Geographic Information Systems (GIS). The goal is to facilitate the finding of optimal solutions for the development of the infrastructure on a regional or national level. It will be discussed how "Functional models" could support coherent risk and sustainability (Risk Analysis, Life Cycle Assessment/Life Cycle Costing) assessments. By using functional decomposition it is possible at a high level (which means from an early design stage onward) to compare alternative solutions for performing the necessary system functions with respect to safety, reliability, environmental impact, and costs.

\section{The supply chain}

Hydrogen is not an energy source in itself and has to be produced from e.g. natural gas using steam reforming or water using large-scale electrolyser and windmill power, as indicated in Fig. 1.

From the production site, the hydrogen may be transported by different means, as pipelines, trucks and/or ships to regional and local storage facilities. The latter ones may be placed directly at the HRS or industrial/domestic sites. The supply chain needs to have storages of different size to store the various amounts of hydrogen on regional or local scale for later use, such as small and large-scale pressurized storage or cryogenic storages.

\section{Methodology}

In the following the method of Functional modelling [21,22] is described using the example of the hydrogen supply and distribution chain presented in Fig. 1. The modelling may be followed by performing a high level risk analysis using the concept hazard analysis concept [22,23], which is described in 


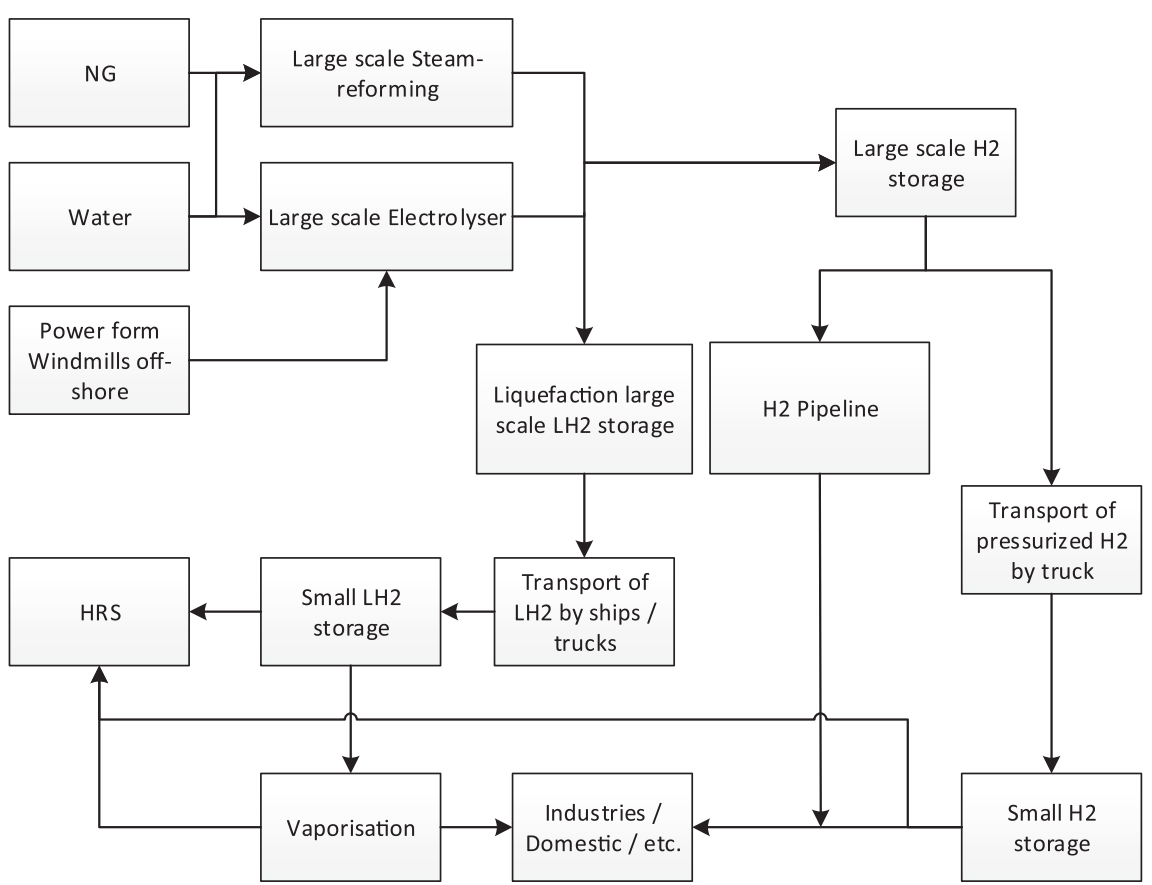

Fig. 1 - Hydrogen supply and distribution chain.

Section 4.1. It is further shown how this could be detailed using HazOP in Section 4.1.1. For comprehensive decision support the application of Geographic Information Systems (GIS) and Life Cycle Assessment (LCA) in connection with functional modelling are briefly discussed in Sections 4.2 and 4.3 , respectively.

\section{Functional analysis}

The assessment of infrastructures benefits from high-level hazard identification methods. The system is first analysed using a functional breakdown and followed by a hazard identification method. Here, the method of "Functional modelling" as described by Rasmussen \& Whetton [22] is chosen and described. Another practical example applying the method can be found in Ref. [24]. The methodology is based on the view that an infrastructure is to be seen as a socio-technical system.

In order to identify hazards as early as possible during planning and design of the future hydrogen infrastructure a functional breakdown and high-level identification of hazards are valuable first steps in an assessment. Methods like FMEA and HazOp are less suited for hazard identification in the very early phases, because they are designed to deal with detailed designs of components and hazards closely related to the technical hardware. As pointed out by Rasmussen \& Whetton [22], these methods only partially account for hazards related to interaction between the different equipment, operator interactions, software, organizational structure and management factors at plant level. These interactions are becoming even more pronounced for an infrastructure like a fully integrated hydrogen supply and distribution network.

In Fig. 2, the generic framework to apply the functional modelling is shown. The idea is that a set of functions are needed to establish a plant or supply chain. Such a sociotechnological system implements hardware, software, operations, work organization and other aspects related to the infrastructure. The functional modelling assumes each function "Fx" as an object that fulfils an "Intent" or goal. The "Intent" is associated with "Methods" and "Constraints" that allow to realize or to limit the "Intent", respectively. The Methods and Constraints themselves can be seen as objects, which can be further decomposed into a hierarchy of other lower level Intents.

The starting point FO in our context is the whole hydrogen supply chain. The first breakdown to level F1...n will be the Intents that make the supply chain work and deliver safely. The next levels F11...Fnn further decompose the Intents from the above level into increasingly more detailed elements. The functional breakdown continues until the system's hazardous areas may be identified with reasonable precision using (high level) hazard identification methods, as described below. Thus, comprehensive hazard identification at design stage is possible using the principles of functional modelling. The processes, inputs, outputs and methods are described, usually graphically, and this graphical model is used to analyse the consequences of deviations in each of the elements in the model. The functional model is hierarchal, which allows analysis to start at top level, and detailed analysis for those elements or process steps that require further attention. Hereunder, the method is extendable to include the detailed technical or organizational solutions that will be implemented at the later phases of the development of the hydrogen supply chain.

Therefore, the main objective of the functional modelling is to identify at each level the parts where further analysis is required. By that the functional decomposition need to ensure that all relevant activities are incorporated like the various processing, storage and transport steps, the established safety 


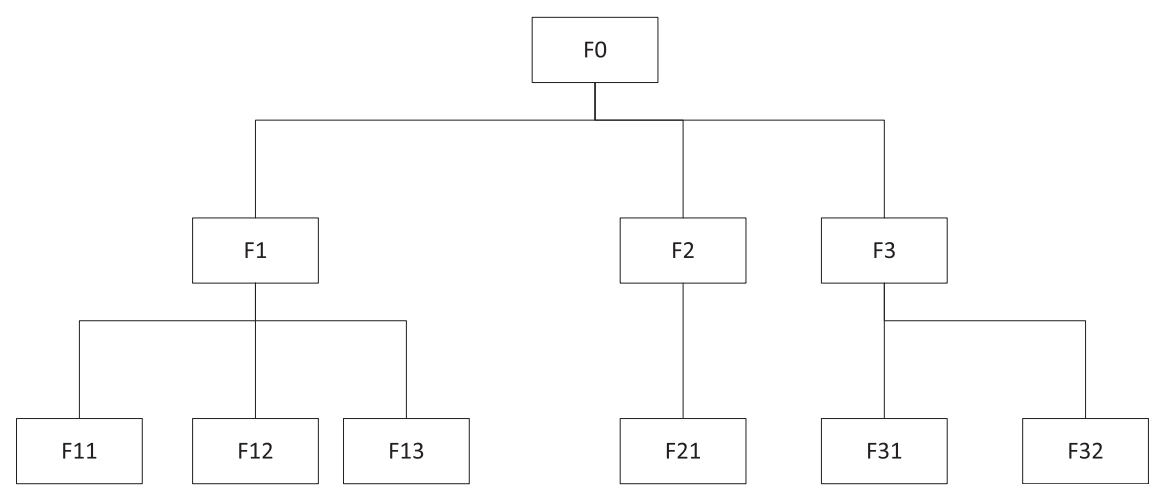

Fig. 2 - Generic functional breakdown.

functions, the emergency systems, the controlling software and others. If necessary, the decomposing can be continued into very detailed items, which then can be analysed through the application of low level hazard identification methods, as e.g. FMEA and HazOp.

Summarizing, the analyst will go through the hydrogen supply chain looking for each level $\mathrm{F}$ by asking the question: How is the "intent" performed, by what "methods" and under which "constraints"? In addition, inputs and outputs of the intent should be well identified (Ref. Fig. 3 and Table 1).

The functional model uses the SADT (Structured Analysis and Design Technique) [25], also known as IDEF0 [26] (or one of the other IDEF dialects) as included in Microsoft Visio ${ }^{\circledR}$. The SADT uses an "ICOM" function block, where ICOM normally stands for Input-Control-Output-Method. In our hazard modelling we prefer to interpret the Control as a "Constraint" (the control function can be included in the Method, see Fig. 3.). A typical example of a high-level constraint would be: "not endangering human life and the environment".

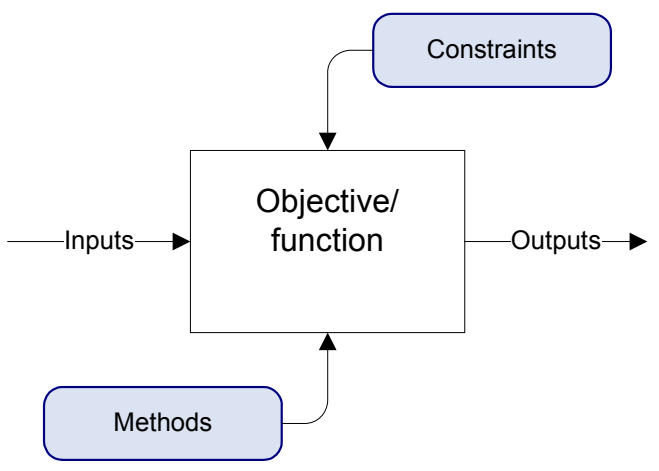

Fig. 3 - Functional modelling for hazard identification.

This function block can be interpreted as:

Do $<$ Objective $>$ by $<$ Methods $>$ respecting $<$ Constraints $>$

Or:

Produce $<$ Outputs $>$ from $<$ Inputs $>$ by $<$ Methods $>$ respecting $<$ Constraints $>$

Hierarchy is introduced by expanding each Method as a Function (a child function of the function it contributes to). For a hydrogen supply chain the "Intent F1" "production of hydrogen" may be modelled as shown in Fig. 4. The example is a generic approach to hydrogen production, as in the early design concepts the specific method may not be decided on. This is possible, as each method can be further developed using a functional breakdown.

\section{Functional modelling of a hydrogen supply and distribution chain}

Applying the principles discussed in Section 3.1 on the example of a hydrogen supply and distribution chain presented in Fig. 1, the following functional model is established as shown in Fig. 5. Originally, the method deals with one technical solution, but as shown here also production of hydrogen by more than one method may be included and analysed. The overall intent FO of the infrastructure is "Hydrogen supply \& use", which is divided into four functions for production, transport, storage and use (F1 to F4). Each of the function may be implemented by various options, as e.g. the "Hydrogen production" F1 may be provided by "Steam reforming" (F11) and/or "Electrolysis" (F12). In a final supply chain, the hydrogen production may be provided by both methods or they could be alternatives that are being compared to find the best solution. The intent F4 "Hydrogen use" is elaborated in more details to exemplify the functions that are part of a HRS (F41) and it indicates the possibility to include detailed modelling of e.g. constraints for F41 "facility control" as F4143 "Maintenance \& Training".

Besides a graphical representation to show the relationship of the functions, the functional model may be stored in tabular form as shown in Table 1. The latter form is very convenient for storage in databases, which provides the possibility of advanced data analysis. It also enables the linkage of additional data tables to enable a more comprehensive data storage, e.g. data from a risk analysis, geographical data or inventory data for a live cycle analysis.

\section{Methods for hazard and risk analysis}

There is a plethora of methods available to perform hazard identification and hazard analysis, see for an overview the informative sections of [27]. Traditional hazard identification 
Table 1 - Example of presentation of the functional model in tabular form [23]. The rows in this table are arbitrary functions from Fig. 5.

\begin{tabular}{|c|c|c|c|c|c|}
\hline Code & Inputs & Intent & Method & Constraints & Outputs \\
\hline F12 & $\begin{array}{l}\text { Electrical power } \\
\text { Water } \\
\text { Etc. }\end{array}$ & Hydrogen production & Electrolyser & $\begin{array}{l}\text { Max. pressure } \\
\text { Availability of } \\
\text { cheap power sources } \\
\text { Hydrogen quality } \\
\text { Etc. }\end{array}$ & $\begin{array}{l}\text { Hydrogen } \\
\text { Oxygen } \\
\text { Etc. }\end{array}$ \\
\hline F21 & $\begin{array}{l}\text { Hydrogen gas } \\
\text { Engine fuel } \\
\text { Etc. }\end{array}$ & Hydrogen transport & Truck & $\begin{array}{l}\text { Max. pressure } \\
\text { Route planning } \\
\text { ADR regulation } \\
\text { Etc. }\end{array}$ & $\begin{array}{l}\text { Hydrogen gas } \\
\text { Engine pollutants } \\
\text { Etc. }\end{array}$ \\
\hline F3 & $\begin{array}{l}\text { Hydrogen gas } \\
\text { Energy } \\
\text { Etc. }\end{array}$ & $\begin{array}{l}\text { Hydrogen storage at } \\
\text { large amounts }\end{array}$ & $\begin{array}{l}\text { Cryogenic storage } \\
\text { Pressurized storage }\end{array}$ & $\begin{array}{l}\text { Max. pressure } \\
\text { Temperature control } \\
\text { Evaporation control }\end{array}$ & $\begin{array}{l}\text { Hydrogen gas/liquid } \\
\text { Engine pollutants } \\
\text { Etc. }\end{array}$ \\
\hline F4141 & $\begin{array}{l}\text { Data } \\
\text { Power; } \\
\text { Etc. }\end{array}$ & $\begin{array}{l}\text { (HRS) remote control } \\
\text { signals }\end{array}$ & $\begin{array}{l}\text { Internet/software } \\
\text { HRS safety functions } \\
\text { Surveillance: } \\
\text { Detection \& } \\
\text { Alarm } \rightarrow \text { Decision } \\
\rightarrow \text { Action } \\
\text { Communication } \\
\text { Training }\end{array}$ & $\begin{array}{l}\text { On-line uninterrupted } \\
\text { power supply, knowledge } \\
\text { on specific HRS } \\
\text { intercultural } \\
\text { understanding Etc. }\end{array}$ & Control of HRS \\
\hline
\end{tabular}

methods include HazOp and FMEA, for which normative guidance is available $[28,29]$. Further analysis of accident scenarios are traditionally performed using Fault Tree and Event Tree techniques [27]. Alternative methods include the use of safety-barrier diagrams with clear advantages in terms of readability and communication to non-experts [30,31], and Discrete Event Simulation, allowing for dynamic event trees [32]. In the following, Concept Hazard Analysis is described which provides high-level analysis of a technical system.

\section{Concept hazard analysis}

The next step following the functional breakdown is risk analysis. For this, traditional hazard identification methods could be used such as Checklists or What-if questions. Nevertheless, as originally suggested by Wells et al. [23] and adapted by Rasmussen \& Whetton [22] the functional breakdown may be analysed for hazardous areas using the method "Concept Hazard Analysis" (CHA). The method may be used in early stages of planning and design of a supply chain and need only

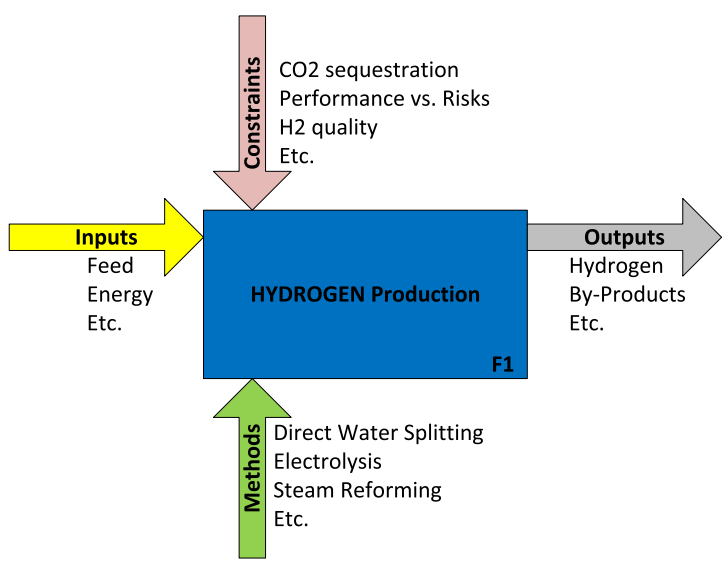

Fig. 4 - Example for Intent F1 "Hydrogen production". block diagrams or preliminary process flow diagrams as input. The method's aim is to identify the main hazards. Based on the achieved functional breakdown of our system for each area keywords are applied that the group of analysts have agreed on. The keywords are addressing generic issues, as shown in Table 2. Therefore, the team performing CHA has to adopt a set of relevant specific keywords for the given analysis (Table 3).

More detailed analysis using $\mathrm{HazOp}$

As discussed above HazOp is a method that can be used when the functional breakdown is sufficiently detailed. The method is applied very successfully in process systems regarding the flow of a material through the system [28]. By that the consequences caused by deviations in the systems are systematically recorded. The drawback is the huge demand of resources (persons, time) and the complexity of the outcome, which is not fulfilling the requirements behind the functional modelling philosophy. Nevertheless, HazOp is a top-down technique that would fit nicely to the hierarchical structure of a functional decomposition. The elegance of HazOp is that it allows combining the relevant characteristics with guide words (such as No, More, Less, Reverse, Late, Before...) in order to generate possible deviations. Solving hazards can be assigned to methods in the functional model, or by choosing the right implementation to fulfil an intent. Therefore, with some adoptions to the HazOp method, it should be possible to apply the method in the context of the higher levels of functional modelling. The properties of the outputs, inputs, constraints and methods could be similar combined with modified guide words (e.g. guideword "no" + "method x" means method X is not performed). This is a novel idea of performing HAZID by means of functional modelling, which is more rigorous compared to Whetton's Concept Hazard Analysis, which originally was suggested to be applied with the functional model, but does not exploit the functional decomposition optimally. 


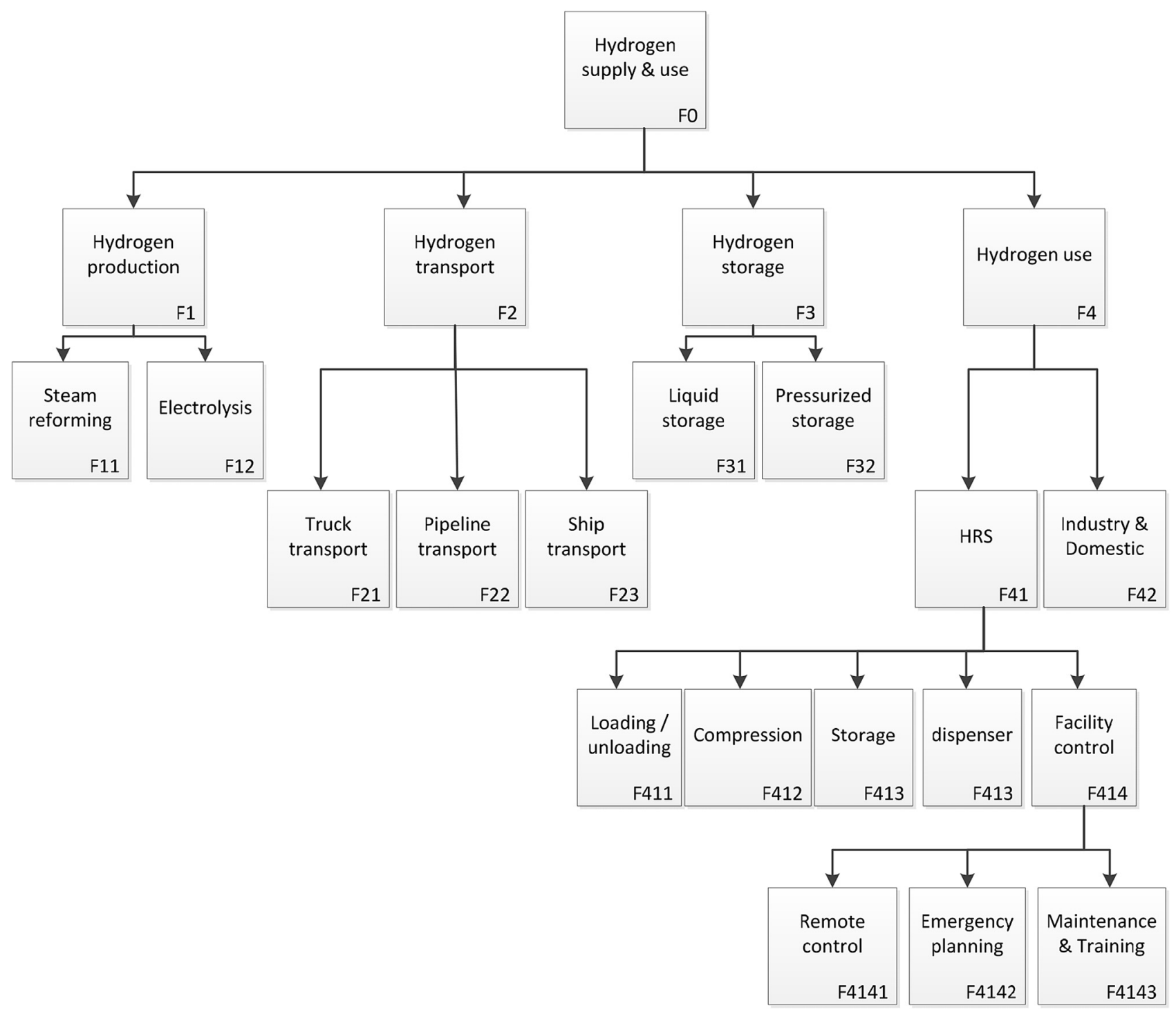

Fig. 5 - Example of a functional breakdown of the hydrogen supply and distribution chain.

Table 2 - Examples for generic keywords used in "Concept Hazard Analysis" [23].

\begin{tabular}{|c|c|c|c|}
\hline Flammables & $\begin{array}{l}\text { Ignition } \\
\text { Fire } \\
\text { Explosion/detonation }\end{array}$ & Mechanical hazards & $\begin{array}{l}\text { Structural hazards } \\
\text { Collapse, drop }\end{array}$ \\
\hline Chemicals & $\begin{array}{l}\text { Toxicity } \\
\text { Corrosion } \\
\text { Off-specification }\end{array}$ & Mode of operation & $\begin{array}{l}\text { Start-up/Shutdown/Abnormal } \\
\text { Maintenance } \\
\text { Emergency }\end{array}$ \\
\hline Pollutants & $\begin{array}{l}\text { Emissions } \\
\text { Effluents } \\
\text { Ventilation }\end{array}$ & Release of material & $\begin{array}{l}\text { Release on rupture } \\
\text { Release by discharge } \\
\text { Fugitive/periodic emissions }\end{array}$ \\
\hline Health hazards & $\begin{array}{l}\text { Chemical contact } \\
\text { Noise }\end{array}$ & Loss of services & $\begin{array}{l}\text { Electricity } \\
\text { Water }\end{array}$ \\
\hline Electrical/radiation hazards & $\begin{array}{l}\text { Electrical } \\
\text { Radiation } \\
\text { Laser }\end{array}$ & External threats & $\begin{array}{l}\text { Accidental impact; Extreme weather } \\
\text { Loosening/Vibration } \\
\text { Sabotage/Theft }\end{array}$ \\
\hline Thermodynamic hazards & $\begin{array}{l}\text { Over-/under-pressure } \\
\text { Over-/under-temperature }\end{array}$ & & \\
\hline
\end{tabular}


Table 3 - Analysis of the found intents (I), methods (M) and constraints (C) using selected keywords from CHA.

\begin{tabular}{|c|c|c|c|c|c|c|c|}
\hline \multicolumn{3}{|c|}{ Function } & \multicolumn{5}{|c|}{ Concept hazard analysis } \\
\hline Ref & $\mathrm{T}$ & Description & Keyword & Main variance & Consequences & Mitigation & Notes \\
\hline F12 & M & Water electrolysis & Chemicals: Corrosion & Release $\rightarrow$ Fire & $\begin{array}{l}\text { Heat radiation } \\
\text { on equipment }\end{array}$ & ATEX & \\
\hline F21 & $\mathrm{M}$ & $\begin{array}{l}\text { Truck transport } \\
\text { (pressurized) }\end{array}$ & $\begin{array}{l}\text { External: Accidental } \\
\text { impact due to obstacle } \\
\text { collision }\end{array}$ & $\begin{array}{l}\text { Structural damage: } \\
\rightarrow \text { leakage } \\
\rightarrow \text { insulation }\end{array}$ & $\begin{array}{l}\text { Release of } \\
\text { hydrogen/ } \\
\text { overpressure in } \\
\text { cryogenic system } \\
\text { Tank rupture }\end{array}$ & $\begin{array}{l}\text { Fences } \\
\text { authorization } \\
\text { to enter }\end{array}$ & $\begin{array}{l}\text { Depends on } \\
\text { storage type }\end{array}$ \\
\hline F3 & I & Hydrogen storage & $\begin{array}{l}\text { Thermodynamic hazards: } \\
\text { over temperature due } \\
\text { to external fire }\end{array}$ & Weakening of walls & $\begin{array}{l}\text { Tank rupture } \\
\text { Release of hydrogen }\end{array}$ & $\begin{array}{l}\text { Fences } \\
\text { Safety distance }\end{array}$ & \\
\hline F4141 & $\mathrm{C}$ & $\begin{array}{l}\text { On-line with data } \\
\text { connection }\end{array}$ & $\begin{array}{l}\text { Mode of operation: } \\
\text { Abnormal }\end{array}$ & $\begin{array}{l}\text { Off-line } \rightarrow \text { Loss of } \\
\text { control of HRS }\end{array}$ & $\begin{array}{l}\text { Possible escalation } \\
\text { of minor events }\end{array}$ & $\begin{array}{l}\text { High SIL level } \\
\text { local operation }\end{array}$ & $\begin{array}{l}\text { HRS shuts } \\
\text { automatically } \\
\text { down on loss of } \\
\text { data connection }\end{array}$ \\
\hline
\end{tabular}

\section{Application of geographic information systems GIS}

An important issue, when analysing hydrogen supply and distribution networks, is the knowledge about the specific geographical positions of the hazardous areas to evaluate for social risk criteria. This is closely related to decisions on additional preventive and mitigating measures to ensure the acceptance criteria for a given installation. It is important to know about the population density, the environmental vulnerability and the location of hospitals, emergency service etc. along the networks. For this GIS is a very efficient and valuable tool (see e.g. Refs. $[33,34]$ as it allows to superimpose thematic maps and to analyse for e.g. the population density for any geographical position). It is straightforward to model the hydrogen supply and distribution networks with a GIS environment using established geographical maps and CAD drawings from the planning state of the networks. As the functional model regards the intents as objects, it is possible to attach graphical object(s) with an intent and by that to preserve the geographical position together with the attributes listed in the table form of the results of the functional model and the results of hazard identification tables.
For a quantitative risk assessment, data on the system state (amounts, pressures, temperature, etc.) could as well be attached to the graphical objects supporting consequence assessments, while other necessary parameters as e.g. weather data and population densities could be provided by respective thematic maps.

\section{Life cycle assessment and life cycle costing}

Establishing sustainable hydrogen supply and distribution networks, decision support has also to be provided concerning the environmental aspects and the economic aspects of sustainability using the methods of Life Cycle Assessment (LCA) and Life Cycle Costing (LCC). The LCA method has been standardized by ISO standards [35]. The steps to perform the assessment according to the ISO standard involve 1) a goal and scope definition and is defining the fuel unit (called functional unit, e.g. the amount of hydrogen to fill a fleet of 1000 vehicles) that is followed through the different stages of the life cycle of the fuel, as shown in Fig. 6. Each stage will have an environmental impact due to the respective processes, amount of energies and materials used in each stage. The second step is to establish a comprehensive inventory for

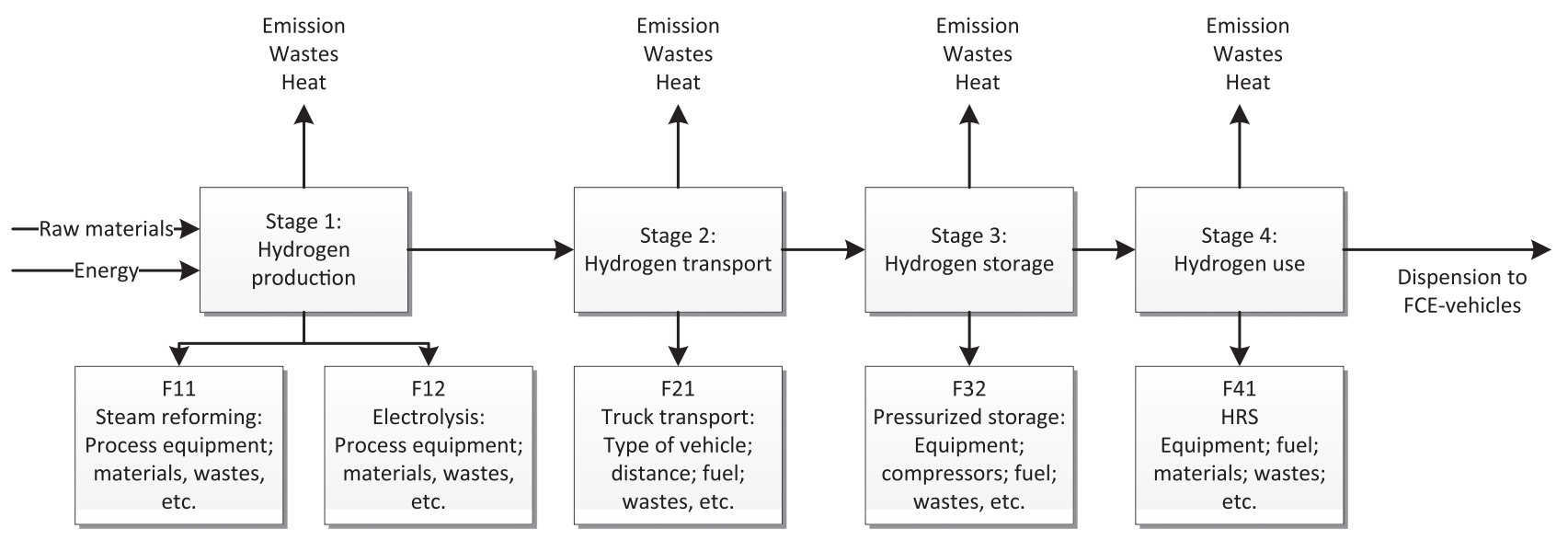

Fig. 6 - LCA/LCC assessment for a fuelling system: Stages and indication of detailed input. 
all the materials going into and out of the stages and energies used. The third step is an impact assessment to predict environmental and human effects of the effluents and the resources used. For each step, the results are interpreted and finally all results may be aggregated into a "single score".

Similar the LCC method [36] is modelling the costs of the stages. The calculation is applying the same model that has been used for the LCA (Fig. 6).

The functional model (Fig. 5) and the LCA/LCC model may be structured in the same way to ensure model compatibility. By that the functions F1 to F4 are directly comparable to the stage $1-4$ of the LCA/LCC. Therefore, the input and output data necessary for the LCA inventory may be linked to the output tables of the functional model.

\section{Discussion and conclusion}

The paper presents the method of functional modelling for a hydrogen supply chain including high level risk assessment that may be enhanced by other decision support tools as e.g. HazOp, GIS, LCA and LCC. The presentation of the results for the functional breakdown may be in tabular form or as a functional graph. The first form is feasible for storage in databases, while the latter form is easier to overview by human analysts. The data for each function Fx may be linked to spatial data and implemented as a GIS database, where the geographical information is preserved along with the detailed technical information. This enables the option of spatial analysis readily available in GIS systems. By that, the analysis can be easily extended using additional thematic maps (e.g. on population densities or vulnerable ecosystems). This facilitates the identification of vulnerable objects and risk calculations to establish risk indicators as e.g. the societal risk (FN-curves).

The risk assessment of a complete supply chain can be analysed using the functional modelling approach and the conceptual hazard analysis methodology. The high-level risk analysis enables the efficient risk assessment and it helps to restrict the assessment to the hazardous areas of concern. The functional modelling allows the modelling of new designed technologies and may grow more and more detailed as new information and alternative technologies are implemented. At a certain level there is a transition where a low level assessment (e.g. application of FMEA and HazOp) becomes appropriate, which is easily handled by the approach. This is an important feature for assessments of emerging technologies, as it allows for easy implementation of new knowledge on the technology.

For a holistic decision support other sustainability aspects as the environment and economy are needed and they should be based on the same detailed model to ensure consistent modelling of systems. It is discussed that the basic functional model used for the risk assessment can be re-used for the LCA/LCC and by that, the functional model database may also be used as the comprehensive database to store other data relevant for other decision support methods. Cloud solutions could be the platform for creating a single point access for the experts working with the decision support of a specific system. This is likely to improve the quality of the calculations and reports as it could ensure usage of consistent and the latest data, when single place storage and maintenance of the needed data and assumptions is implemented.

\section{R E F E R E N C E S}

[1] Zhiyong L, Xiangmin P, Jianxin M. Quantitative risk assessment on a gaseous hydrogen refueling station in Shanghai. ISMF-09, Int Symp Multiph Flow, Heat Mass Transf Energy Convers 2010;35(13):6822-9.

[2] Kikukawa S, Mitsuhashi H, Miyake A. Risk assessment for liquid hydrogen fueling stations. Int J Hydrogen Energy 2009;34(2):1135-41.

[3] Aprea JL. Hydrogen energy demonstration plant in Patagonia: description and safety issues. Int J Hydrogen Energy 2009;34(10):4684-91.

[4] Rosyid OA, Jablonski D, Hauptmanns U. Risk analysis for the infrastructure of a hydrogen economy. Int J Hydrogen Energy 2007;32(15):3194-200.

[5] Pasman H, Reniers G. Past, present and future of Quantitative Risk Assessment (QRA) and the incentive it obtained from Land-Use Planning (LUP). J Loss Prev Process Ind Apr. 2014;28:2-9.

[6] Vianello C, Maschio G. Quantitative risk assessment of the Italian gas distribution network. J Loss Prev Process Ind 2014;32(0):5-17.

[7] Baesi S, Abdolhamidzadeh B, Hassan CRC, Hamid MD, Reniers G. Application of a multi-plant QRA: a case study investigating the risk impact of the construction of a new plant on an existing chemical plant's risk levels. J Loss Prev Process Ind 2013;26(5):895-903.

[8] Zachmann G, Holtermann M, Radeke J, Tam M, Huberty M, Naumenko D, et al. The great transformation: decarbonising Europe's energy and transport systems, vol. XVI; 2012.

[9] Caputo AC, Pelagagge PM, Salini P. Impact of accidents risk on hydrogen road transportation cost. Int J Energy Sect Manag 2011;5(2):215-41.

[10] Kim J, Moon I. The role of hydrogen in the road transportation sector for a sustainable energy system: a case study of Korea. Int J Hydrogen Energy 2008;33(24):7326-37.

[11] Dayhim M, Jafari MA, Mazurek M. Planning sustainable hydrogen supply chain infrastructure with uncertain demand. Int J Hydrogen Energy 2014;39(13):6789-801.

[12] Agnolucci P. Hydrogen infrastructure for the transport sector. Int J Hydrogen Energy 2007;32(15):3526-44.

[13] Andrews J, Shabani B. Re-envisioning the role of hydrogen in a sustainable energy economy. 10th Int Conf Clean Energy 2010 2012;37(2):1184-203.

[14] Parkes KR. Shift schedules on North Sea oil/gas installations: a systematic review of their impact on performance, safety and health. Saf Sci 2012;50(7):1636-51.

[15] Stephens-Romero SD, Brown TM, Kang JE, Recker WW, Samuelsen GS. Systematic planning to optimize investments in hydrogen infrastructure deployment. Nov Hydrog Prod Technol Appl Nov Hydrog Prod Technol Appl 2010;35(10):4652-67.

[16] Smitkova M, Janíček F, Riccardi J. Life cycle analysis of processes for hydrogen production. Int J Hydrogen Energy 2011;36(13):7844-51.

[17] Cetinkaya E, Dincer I, Naterer GF. Life cycle assessment of various hydrogen production methods. Int J Hydrogen Energy 2012;37:2071-80.

[18] Leveson N. A new accident model for engineering safer systems. Saf Sci 2004;42(4):237-70.

[19] Bedford T, Cooke RM. Probabilistic risk analysis foundations and methods. Cambridge: Cambridge University Press; 2001. 
[20] Aven T, Reniers G. How to define and interpret a probability in a risk and safety setting. Saf Sci Jan. 2013;51(1):223-31.

[21] Rasmussen B, Petersen KE. Plant functional modelling as a basis for assessing the impact of management on plant safety. Reliab Eng Syst Saf 1999;64:201-7.

[22] Rasmussen C, Whetton B. Hazard identification based on plant functional modelling. Reliab Eng Syst Saf 1997;55:77-84.

[23] Wells G, Wardman M, Whetton C. Preliminary safety analysis. J Loss Prev Process Ind Jan. 1993;6(1):47-60.

[24] Duijm NJ. Hazard analysis of technologies for disposing explosive waste. J Hazard Mater 2002;90:123-35.

[25] Ross DT. Structured analysis for requirements definition. IEEE Trans Softw Eng 1977;SE-3(1):6-15.

[26] ICAM architecture Part II-Volume IV - function modeling manual (IDEFO). Ohio 45433: Wright Patterson Airforce Base; 1981.

[27] ISO. IEC/ISO 31010:2009: risk management - risk assessment techniques, vol. 2010E. Brussels: CENELEC; 2010.

[28] IEC. Hazard and operability studies (HAZOP studies) application guide, IEC 61882:2001. IEC; 2001.
[29] IEC. Analysis techniques for system reliability - procedure for failure mode and effect analysis (FMEA). Brussels: CENELEC; 2006.

[30] Duijm NJ. Safety-barrier diagrams as a safety management tool. Reliab Eng Syst Saf 2009;94(2):332-41.

[31] Duijm NJ, Markert F. Safety-barrier diagrams as a tool for modelling safety of hydrogen applications. 2nd Int Conference Hydrog Safety 2009;34(14):5862-8.

[32] Kozine I, Markert F, Alapetite A. Discrete event simulation in support to hydrogen supply reliability. In: 3rd International Conference on Hydrogen Safety, vol. 3. CEA; 2009. p. 159.

[33] Verter V, Kara BY. A GIS-based framework for hazardous materials transport risk assessment. Risk Anal Dec. 2001;21(6):1109-20.

[34] Rigina O. Regional radiation risk and vulnerability assessment by integration of mathematical modelling and GIS analysis. Environ Int 2002;27(7):527-40.

[35] Miljøledelse - Livscykulusvurdering - Principper og struktur. Dansk Standard; Jan. 2006.

[36] Hunkeler D, Lichtenvort K, Rebitzer G. Environmental life cycle costing. Pensacola (Fla.): CRC Press SETAC; 2008. 